\title{
Mcl-1: a highly regulated cell death and survival controller
}

\author{
Hsin-Fang Yang-Yen* \\ Institute of Molecular Biology, Academia Sinica, 128 Yen-Jiou Yuan Road, Section 2, Nankang, Taipei, \\ 11529, Taiwan \\ (c) 2006 National Science Council, Taipei
}

Key words: Mcl-1, cell death, survival signals

\section{Summary}

Mcl-1 is one member of the Bcl-2 family that has a very short protein half-life. Since its identification in 1993, a great number of studies have implicated that Mcl-1 plays an important role in various cell survival pathways. However, not until recently did the molecular mechanism by which Mcl-1 antagonizes apoptosis have begun to be elucidated. Mcl-1 is rapidly degraded in response to cell death signals and is immediately re-induced by survival stimuli. These results indicate that Mcl-1 plays an apical role in many cell death and survival regulatory programs.

\section{Mcl-1 is up-regulated by many cytokines and growth factors}

The $m c l-1$ gene was originally identified in the ML1 human myeloid leukemia cell line which underwent phorbol ester-induced differentiation [1]. Later studies indicate that Mcl-1 expression can also be stimulated by many growth factors or cytokines including interleukin-3 (IL-3), IL-5, IL-6, IL-7, granulocyte-macrophage colony-stimulating factor (GM-CSF), vascular endothelial growth factor, alpha interferon, and epidermal growth factor [2-8]. Except for IL-3 and phorbol ester, the signaling pathway triggered by other cytokines or growth factors, which leads to upregulation of Mcl-1 expression, remains largely undefined. Using IL-3 dependent $\mathrm{Ba} / \mathrm{F} 3$ cell as a model system, the up-regulation of Mcl- 1 expression by IL-3 was found to be at the transcriptional level [3]. IL-3 stimulated transcription of $m c l-1$ is mainly mediated through activation of two transcription factor complexes each recognizing a promoter element designated SIE or CRE-2 site

*To whom correspondence should be addressed. Tel: +886-22789-9228; Fax + 886-2-2782-6085; E-mail: imbyy@gate.sinica.edu.tw
[9]. Interestingly, activation of these two promoter elements by IL-3 is mediated through two different, but cooperative pathways. While IL-3 stimulation does not change the DNA binding activity of the SIE-binding complex, it increases the transactivation activity of this complex via phosphorylation of PU.1 in a P38 mitogen-activated protein kinase-dependent pathway [10]. On the other hand, IL-3 stimulation increases the DNA binding activity of the CRE-2 binding complex via phosphorylation of CREB in a PI3-K/AKT dependent pathway [9]. Of note, of these two IL3 responsive elements, only the SIE element is relatively more conserved in the human $\mathrm{mcl}-1$ gene [11]. Interestingly, the SIE-like element found in the human gene promoter $(-107$ region) was shown to bind to SRF/Elk-1 and mediate the TPA-induced expression of the $m c l-1$ reporter in human K562 cells [11].

\section{Mcl-1 is a labile protein}

Mcl-1 is one unique member of the Bcl-2 family in that it has a very short half-life, ca. $30-40 \mathrm{~min}$ when measured by the pulse-chase analysis [3, 12], 
and ca. 90 min when measured by the cycloheximide blocking method [13]. The reason for the discrepancy between these two measurements was not clear. But, the identification of three isoforms of Mcl-1 with different half-lives, i.e., 1-3 $\mathrm{h}$ for the two bands with slower mobility and a longer halflife for the third one with faster migrating ability in the SDS-PAGE [14], suggests that the newly synthesized and the mature forms of Mcl-1 have different turnover rates. In both hematopoietic cell lines $\mathrm{TF}-1$ and $\mathrm{Ba} / \mathrm{F} 3$, it is always the slowest migrating form that is induced upon cytokine stimulation [3, 10]. Furthermore, it is this form that co-migrates with the newly synthesized protein (unpublished observation). Taken together, these results suggest that the faster migrating forms may be the proteolytic fragments of the newly synthesized one. Although the identity and functions of all Mcl-1 isoforms remain to be determined, a recent report suggests that the slower migrating doublets of $\mathrm{Mcl}-1$, which are localized to nucleus, may have a growth suppression function [15].

The Mcl-1 protein level quickly decreases in response to signals that trigger cell death, such as growth factor withdrawal [3], UV treatment [12], and viral infection [16]. In the first two cases, the death signals lead to the inhibition of Mcl-1 synthesis, whereas the Mcl-1 turnover rate remains the same [3, 12]. In contrast, it was shown that adenovirus infection stimulates proteasome-mediated turnover of Mcl-1, shortening its half-life from more than $4 \mathrm{~h}$ to less than $2 \mathrm{~h} \mathrm{[16].} \mathrm{The} \mathrm{E3}$ ligase (Mule/ARF-BP1) which catalyzes polyubiquitination of Mcl-1 in the ubiquitin dependent proteasome degradation pathway has been recently identified [17, 18]. The same E3 ligase can also catalyze ubiquitination of other proteins including p53 [19] and histone [20]. It remains to be determined whether the Mule/ARF-BP1E3 ubiquitin ligase activity is differentially regulated by various death signaling pathways.

\section{Mcl-1 interacting proteins}

Many proteins are reported to be able to interact with Mcl-1. Majority of such interacting proteins belong to the Bcl-2 protein family that includes the multidomain pro-apoptotic members, Bax and Bak, and the BH3-only proteins, such as Bim,
Puma and Noxa [7, 21, 22]. A recent study indicates that in healthy cells, Mcl-1 together with another pro-survival Bcl-2 member, Bcl-XL, sequester the proapoptotic Bak in an inactive state [23]. Cells then undergo apoptosis upon receiving cytotoxic signals that activate certain BH3-only proteins (such as Noxa plus Bad) that can displace Bak from both Mcl-1 and Bcl-XL, [23]. This result together with the fact that Mcl-1 is quickly degraded in response to many death signals [3, $12,16]$ and that its immediate inducibility by survival factors $[3,4,9]$ indicate that Mcl-1 plays an apical role in many cell survival and death regulatory programs.

In addition to the pro-apoptotic Bcl-2 family members, Mcl-1 has been demonstrated to interact with other proteins including proliferating-cell nuclear antigen (PCNA) [24], translationallycontrolled tumor protein TCTP (also known as fortilin) [13, 25], tankyrase 1 [26] and cyclin dependent kinase 1 (CDK1) [15]. Mcl-1 was shown to localize to nucleus where it interacts with PCNA. Interestingly, such interaction represses cell cycle progression, but it is not required for Mcl-1's anti-apoptotic activity [24]. It was recently demonstrated that the subcellular distribution of Mcl-1 is closely correlated with the cell growth state. Most Mcl-1 are found to be localized to mitochondria in exponentially growing cells, whereas majority of Mcl-1 reside in nucleus when cells are in a stationary phase [13]. It's not clear how the subcellular distribution of Mcl-1 is regulated. However, the identification of a proteolytic form of Mcl-1 (snMcl-1) that appears in nucleus [15] suggests that post-translational processing of the full-length protein plays a role in regulating Mcl-1's subcellular localization and possibly its functions as well. Of note, the proteolytic form of Mcl-1 was shown to interact with CDK1 and might thus inhibit cell cycle progression [15]. It remains to be determined whether the Mcl-1-PCNA and Mcl-1-CDK1 interactions are mechanistically linked, and what proportion of the physiological functions of Mcl-1 is resulted from such interactions.

Tankyrase 1, a protein with poly(ADP-ribose) polymerase activity, is another Mcl-1 interacting protein identified via a yeast two-hybrid screen [26]. Tankyrase 1 interacts with both the long-form (Mcl-1L) and the splicing variant of Mcl-1 (Mcl1S), and such interaction was shown to inhibit both 
Mcl-1L-mediated cell survival and Mcl-1S-induced cell death [26]. Although tankyrase 1 can downregulate Mcl-1 protein expression in a transient transfection system, no ADP-ribosylation of Mcl-1 was detected. The physiological significance of Mcl-1-tankyrase 1 interaction remains to be determined. In contrast to tankyrase 1, another Mcl-1 interacting protein TCTP recently identified by Liu et al was found to increase the expression levels of Mcl-1 [13]. The increased Mcl-1 protein level in TCTP-overexpressing cells is due to enhanced stability of Mcl-1. Detailed analysis revealed that TCTP stabilizes Mcl-1 through interfering with Mcl-1's degradation by the ubiquitin-dependent proteasome degradation pathway [13]. It's not clear, however, whether TCTP's inhibitory effect on Mcl-1's degradation is due to steric hindrance of the access of the proteasome degradation machinery or due to other activity of TCTP. TCTP is highly conserved during evolution [27], and is implicated in many cellular functions including human allergic response [28], apoptosis [13, 29] and cell growth [30-32]. A recent study demonstrates that the yeast homolog of TCTP is structurally similar to the Mss4/Dss4 family of proteins, which bind to the GDP/GTP free form of Rab proteins and have been termed guanine nucleotide-free chaperones [27]. This result together with the observed Mcl-1 stability enhancement effect suggests that TCTP may serve as a molecular chaperone of Mcl-1[13]. Further biochemical analysis will be required to test this possibility.

\section{Mcl-1 as a potential target for tumor therapy}

Mcl-1 deficiency results in peri-implantational lethality of mouse embryos [33]. Conditional knockout models further indicate that Mcl-1 is required for the development and maintenance of $\mathrm{B}$ and $\mathrm{T}$ lymphocytes, and ensuring the homeostasis of early hematopoietic progenitors [7, 34]. On the other hand, elevated expression of Mcl-1 in leukemia cells correlated well with their resistance to chemotherapeutic agents [35]. Furthermore, Mcl-1 transgenic mice exhibit a high incidence of B-cell lymphoma [36]. All together, these results as well as the short half-lived and highly regulated nature indicate that $\mathrm{Mcl}-1$ expression is pivotal to normal animal development, whereas its deregulation may promote neoplastic transformation.
The latter case suggests that Mcl-1 may potentially serve as a good target for tumor therapy.

\section{Acknowledgements}

This work was supported in part by an intramural fund from Academia Sinica, and by grants NHRI-EX93-9119BN， NSC 92-3112-B-001-016 from National Health Research Institutes and the National Science Council of Taiwan to H.-F. Yang-Yen.

\section{References}

1. Kozopas K.M., Yang T., Buchan H.L., Zhou P. and Craig R.W., MCL1, a gene expressed in programmed myeloid cell differentiation, has sequence similarity to BCL2. Proc. Natl. Acad. Sci. U.S.A. 90: 3516-3520, 1993.

2. Altmeyer A., Simmons R.C., Krajewski S., Reed J.C., Bornkamm G.W. and Chen-Kiang S., Reversal of EBV immortalization precedes apoptosis in IL-6-induced human B cell terminal differentiation. Immunity 7: 667-677, 1997.

3. Chao J.R., Wang J.M., Lee S.F., Peng H.W., Lin Y.H., Chou C.H., Li J.C., Huang H.M., Chou C.K., Kuo M.L., Yen J.J. and Yang-Yen H.F., mcl-1 is an immediate-early gene activated by the granulocyte-macrophage colonystimulating factor (GM-CSF) signaling pathway and is one component of the GM-CSF viability response. Mol. Cell. Biol. 18: 4883-4898, 1998.

4. Huang H.M., Huang C.J. and Yen J.J., Mcl-1 is a common target of stem cell factor and interleukin-5 for apoptosis prevention activity via MEK/MAPK and PI-3K/Akt pathways. Blood 96: 1764-1771, 2000.

5. Jourdan M., De Vos J., Mechti N. and Klein B., Regulation of Bcl-2-family proteins in myeloma cells by three myeloma survival factors: interleukin-6, interferon-alpha and insulin-like growth factor 1. Cell. Death. Differ. 7: 1244-1252, 2000.

6. Leu C.M., Chang C. and Hu C., Epidermal growth factor (EGF) suppresses staurosporine-induced apoptosis by inducing mcl-1 via the mitogen-activated protein kinase pathway. Oncogene 19: 1665-1675, 2000.

7. Opferman J.T., Letai A., Beard C., Sorcinelli M.D., Ong C.C. and Korsmeyer S.J., Development and maintenance of $\mathrm{B}$ and $\mathrm{T}$ lymphocytes requires antiapoptotic MCL-1. Nature 426: 671-676, 2003.

8. Yang T., Buchan H.L., Townsend K.J. and Craig R.W., MCL-1, a member of the BLC-2 family, is induced rapidly in response to signals for cell differentiation or death, but not to signals for cell proliferation. J. Cell. Physiol. 166: 523-536, 1996 .

9. Wang J.M., Chao J.R., Chen W., Kuo M.L., Yen J.J. and Yang-Yen H.F., The antiapoptotic gene mcl-1 is up-regulated by the phosphatidylinositol 3-kinase/Akt signaling pathway through a transcription factor complex containing CREB. Mol. Cell. Biol. 19: 6195-6206, 1999.

10. Wang J.M., Lai M.Z. and Yang-Yen H.F., Interleukin-3 stimulation of mcl-1 gene transcription involves activation of the PU.1 transcription factor through a p38 
mitogen-activated protein kinase-dependent pathway. Mol. Cell. Biol. 23: 1896-1909, 2003.

11. Townsend K.J., Zhou P., Qian L., Bieszczad C.K., Lowrey C.H., Yen A. and Craig R.W., Regulation of MCL1 through a serum response factor/Elk-1-mediated mechanism links expression of a viability-promoting member of the BCL2 family to the induction of hematopoietic cell differentiation. J. Biol. Chem. 274: 1801-1813, 1999.

12. Nijhawan D., Fang M., Traer E., Zhong Q., Gao W., Du F. and Wang X., Elimination of Mcl-1 is required for the initiation of apoptosis following ultraviolet irradiation. Genes. Dev. 17: 1475-1486, 2003.

13. Liu H., Peng H.W., Cheng Y.S., Yuan H.S. and Yang-Yen H.F., Stabilization and enhancement of the antiapoptotic activity of mcl-1 by TCTP. Mol. Cell. Biol. 25: 3117-3126, 2005.

14. Yang T., Kozopas K.M. and Craig R.W., The intracellular distribution and pattern of expression of Mcl-1 overlap with, but are not identical to, those of Bcl-2. J. Cell. Biol. 128: 1173-1184, 1995.

15. Jamil S., Sobouti R., Hojabrpour P., Raj M., Kast J. and Duronio V., A proteolytic fragment of Mcl-1 exhibits nuclear localization and regulates cell growth by interaction with Cdk1. Biochem. J. 387: 659-667, 2005.

16. Cuconati A., Mukherjee C., Perez D. and White E., DNA damage response and MCL-1 destruction initiate apoptosis in adenovirus-infected cells. Genes. Dev. 17: 2922-2932, 2003.

17. Warr M.R., Acoca S., Liu Z., Germain M., Watson M., Blanchette M., Wing S.S. and Shore G.C., BH3-ligand regulates access of MCL-1 to its E3 ligase. FEBS. Lett. 579: 5603-5608, 2005.

18. Zhong Q., Gao W., Du F. and Wang X., Mule/ARF-BP1, a BH3-only E3 ubiquitin ligase, catalyzes the polyubiquitination of Mcl-1 and regulates apoptosis. Cell. 121: 10851095, 2005.

19. Chen D., Kon N., Li M., Zhang W., Qin J. and Gu W., ARF-BP1/Mule is a critical mediator of the ARF tumor suppressor. Cell 121: 1071-1083, 2005.

20. Liu Z., Oughtred R. and Wing S.S., Characterization of E3Histone, a novel testis ubiquitin protein ligase which ubiquitinates histones. Mol. Cell. Biol. 25: 2819-2831, 2005.

21. Chen L., Willis S.N., Wei A., Smith B.J., Fletcher J.I., Hinds M.G., Colman P.M., Day C.L., Adams J.M. and Huang D.C., Differential targeting of prosurvival Bcl-2 proteins by their $\mathrm{BH} 3$-only ligands allows complementary apoptotic function. Mol. Cell. 17: 393-403, 2005.

22. Wang K., Gross A., Waksman G. and Korsmeyer S.J., Mutagenesis of the $\mathrm{BH} 3$ domain of BAX identifies residues critical for dimerization and killing. Mol. Cell. Biol. 18: 6083-6089, 1998.

23. Willis S.N., Chen L., Dewson G., Wei A., Naik E., Fletcher J.I., Adams J.M. and Huang D.C., Proapoptotic Bak is sequestered by $\mathrm{Mcl}-1$ and $\mathrm{Bcl}-\mathrm{xL}$, but not $\mathrm{Bcl}-2$, until displaced by BH3-only proteins. Genes. Dev. 19: 1294 1305,2005 .

24. Fujise K., Zhang D., Liu J. and Yeh E.T., Regulation of apoptosis and cell cycle progression by MCL1. Differential role of proliferating cell nuclear antigen. J. Biol. Chem. 275: 39,458-39,465, 2000.

25. Zhang D., Li F., Weidner D., Mnjoyan Z.H. and Fujise K., Physical and functional interaction between myeloid cell leukemia 1 protein (MCL1) and Fortilin. The potential role of MCL1 as a fortilin chaperone. J. Biol. Chem. 277: 37430-37438, 2002.

26. Bae J., Donigian J.R. and Hsueh A.J., Tankyrase 1 interacts with Mcl-1 proteins and inhibits their regulation of apoptosis. J. Biol. Chem. 278: 5195-5204, 2003.

27. Thaw P., Baxter N.J., Hounslow A.M., Price C., Waltho J.P. and Craven C.J., Structure of TCTP reveals unexpected relationship with guanine nucleotide-free chaperones. Nat. Struct. Biol. 8: 701-704, 2001.

28. MacDonald S.M., Rafnar T., Langdon J. and Lichtenstein L.M., Molecular identification of an IgE-dependent histamine-releasing factor. Science 269: 688-690, 1995.

29. Li F., Zhang D. and Fujise K., Characterization of fortilin, a novel antiapoptotic protein. J. Biol. Chem. 276: 47,542$47,549,2001$

30. Gachet Y., Tournier S., Lee M., Lazaris-Karatzas A., Poulton T. and Bommer U.A., The growth-related, translationally controlled protein P23 has properties of a tubulin binding protein and associates transiently with microtubules during the cell cycle. J. Cell. Sci. 112(Pt 8) 1257-1271, 1999.

31. Tuynder M., Fiucci G., Prieur S., Lespagnol A., Geant A., Beaucourt S., Duflaut D., Besse S., Susini L., Cavarelli J., Moras D., Amson R. and Telerman A., Translationally controlled tumor protein is a target of tumor reversion. Proc. Natl. Acad. Sci. U.S.A. 101: 15,364-15,369, 2004.

32. Yarm F.R., Plk phosphorylation regulates the microtubulestabilizing protein TCTP. Mol. Cell. Biol. 22: 6209-6221, 2002.

33. Rinkenberger J.L., Horning S., Klocke B., Roth K. and Korsmeyer S.J., Mcl-1 deficiency results in peri-implantation embryonic lethality. Genes. Dev. 14: 23-27, 2000.

34. Opferman J.T., Iwasaki H., Ong C.C., Suh H., Mizuno S., Akashi K. and Korsmeyer S.J., Obligate role of antiapoptotic MCL-1 in the survival of hematopoietic stem cells. Science 307: 1101-1104, 2005.

35. Kaufmann S.H., Karp J.E., Svingen P.A., Krajewski S., Burke P.J., Gore S.D. and Reed J.C., Elevated expression of the apoptotic regulator Mcl-1 at the time of leukemic relapse. Blood 91: 991-1000, 1998

36. Zhou P., Levy N.B., Xie H., Qian L., Lee C.Y., Gascoyne R.D. and Craig R.W., MCL1 transgenic mice exhibit a high incidence of B-cell lymphoma manifested as a spectrum of histologic subtypes. Blood 97: 3902-3909, 2001. 